\title{
Beef Carcass Contamination by Shiga Toxin-Producing Escherichia coli Strains in an Abattoir in Brazil: Characterization and Resistance to Antimicrobial Drugs
}

\author{
Everlon Cid Rigobelo, ${ }^{1}$ Edilene Santo, ${ }^{2}$ and Jose Moacir Marin ${ }^{3}$
}

\begin{abstract}
A survey was performed to estimate the frequency of Escherichia coli and Shiga toxin-producing E. coli (STEC) in carcasses obtained from an abattoir in Brazil between February 2006 and June 2007. A total of 216 beef carcasses were sampled at three stages of the slaughter process-preevisceration, postevisceration, and postprocessing-during the rain and dry seasons, respectively. Of the carcasses sampled, $58 \%$ were preevisceration E. coli positive, $38 \%$ were postevisceration positive, and $32 \%$ postprocessing positive. At the postprocessing stage, the isolation of $E$. coli was twice as high in the rain season. E. coli was isolated from 85 carcasses of which only $3(1.4 \%)$ were positive for stx-encoding genes. No E. coli O157 serogroup isolates were detected. No antimicrobial resistance was found in nine of the isolates ( $10 \%$ of the total). The most frequent resistances were seen against cephalothin (78\%), streptomycin (38\%), nalidixic acid (36\%), and tetracycline $(30 \%)$. Multidrug resistance (MDR) to three or more antimicrobial agents was determined in $28(33 \%)$ E. coli isolates. The presence of STEC and MDR strains among the isolates in the beef carcasses emphasizes the importance of proper handling to prevent carcass contamination.
\end{abstract}

\section{Introduction}

$E^{5}$ SCHERICHIA COLI FORM part of the bacterial population of cattle's gastrointestinal tract. During beef carcass processing, the presence of E. coli is an indicator of fecal contamination. Levels of E. coli associated with cattle carcasses may increase or decrease during processing according to the extent of such contamination of the living cattle, efficiency of evisceration, and hygienic practices in the abattoir (Bell, 1997). Increased consumer's concern about beef safety started in 1983 (Riley et al., 1983) and continued to rise in recent years due to the large number of reported outbreaks and sporadic cases of human infections with Shiga toxin-producing
E. coli (STEC) (Hussein and Bollinger, 2005). STEC strains most frequently associated with diseases in the United States and Europe are of the O157:H7 serotype (Nataro and Kaper, 1998; Caprioli et al., 2005). However, several other serotypes (O26, O103, O111, O113, and O121) are also commonly found in association with severe disease outbreaks; in some countries they are isolated more often from clinical cases than O157 (Bettelheim, 2007).

Cattle are considered primary reservoirs of both O157 and non-O157 STEC bacteria (Bettelheim, 2000), and frequently carry STEC without showing pathological symptoms (Blanco et al., 1997). The complete list of bacterial virulence determinants required for STEC's pathological

\footnotetext{
${ }^{1}$ Faculdade de Zootecnia de Dracena, Universidade Estadual Paulista, Ribeirão Preto, Brazil.

${ }^{2}$ Faculdade de Ciências Agrárias e Veterinárias de Jaboticabal, Universidade Estadual Paulista, Ribeirão Preto, Brazil.

${ }^{3}$ Departamento de Morfologia, Estomatologia e Fisiologia, FORP, Universidade de São Paulo-Campus, Ribeirão Preto, Brazil.
} 
effects is not known, although stx appears to be a key factor in pathogenesis (Acheson, 2000). Other virulence factors such as intimin (eae) and hemolysin (hly $\mathrm{A})$ are thought to enhance pathogenicity, but are not required for strains to produce severe disease, including hemolytic uremic syndrome (HUS) (Acheson, 2000; Caprioli et al., 2005). STEC occurrence in feces of healthy or diarrheic cattle in Brazil has been reported with a high prevalence of strains and a great diversity of serotypes (Irino et al., 2005; Rigobelo et al., 2006; Aidar-Ugrinovich et al., 2007; Farah et al., 2007).

Although antimicrobial therapy is an important tool for infection treatment, antimicrobial resistance may become a major problem in veterinary medicine as a consequence of the intensive use or misuse of antimicrobial drugs (Monroe and Polk, 2000). Susceptibility patterns of indicator bacteria obtained from healthy animals have been suggested as good predictors of resistance situation in a bacterial population as a whole (Van den Bogaard and Stobberingh, 2000). During the processing of carcasses, fecal contamination or transfer of bacteria from the animal's hide to the carcass can promote transmission of pathogenic E. coli to food supplies (Bell, 1997; Barkocy-Gallagher et al., 2001). Antimicrobial drug resistance data of fecal E. coli strains from animals were difficult to find in the literature from Brazil, most of them showing high levels of resistance against several antimicrobial agents from commensal E. coli isolated from diarrheic calves (Rigobelo et al., 2006) as well as from STEC strains isolated from meat (Rodolpho and Marin, 2007).

The aim of the present study was to determine the incidence of $E$. coli on beef carcass at three stages of the slaughter process, during the rain and dry seasons; the survey also included assessment of the prevalence of virulence genes and antimicrobial drug resistance in the isolates obtained at a chosen abattoir in Brazil.

\section{Materials and Methods}

\section{Carcass samples}

Two hundred and sixteen samples from bovine carcasses of pasture-raised cattle were collected between February 2006 and June 2007, at a small abattoir in São Paulo State (Dracena city), in southwestern Brazil. The abattoir had a slaughtering capacity of 100 cows per day; after antemortem inspection, healthy cows selected for slaughter rested in the bairage for a day prior to slaughter. Food was withdrawn, but water was given. Carcass sampling was performed according to the abattoir processing plan and permission. Sampling of the feedlot cattle was done on five different occasions, three in the dry and two in the rainy seasons, respectively, during three stages of the carcass handling process, namely, preevisceration, postevisceration, and postprocessing. Preevisceration samples were taken immediately after complete hide removal; postevisceration samples after splitting and trimming; postprocessing samples were taken after washing carcasses hanging in the cooler. Due to an abattoir ruling of its processing plan, all samples were taken from one carcass at only one stage of the process; it was therefore not possible to take samples of the same carcass at different stages of the processing. Each sample was obtained using a Specie-Sponge (3M-Brazil) moistened with sterile $0.1 \%$ peptone water (Basingstoke, Oxoid, UK) in a bag. Sponges were wrung out as much as possible within the bag, withdrawn, and used to swab the rump of each carcass, near the anus, over an area of $10 \times 30 \mathrm{~cm}$, delineated by a sterile metal template placed on the same half of each carcass. Each sponge was immersed in a stomacher bag with $25 \mathrm{~mL}$ of sterile-modified tryptone soy broth (Oxoid) supplemented with $2 \%$ novobiocin (Sigma, St. Louis, MO) (mTSB) and mixed by handling for $2 \mathrm{~min}$. All samples were then taken to the laboratory in an ice-cooled bag and kept for $12 \mathrm{~h}$ at room temperature.

\section{Bacterial isolates}

One hundred microliters of each sample was streaked on a MacConkey agar plate (Oxoid), and incubated at $37^{\circ} \mathrm{C}$ for $24 \mathrm{~h}$. Colonies showing E. coli characteristics were submitted to Gram-staining and identified by standard biochemical tests as oxidase negative, indole positive, Simon's citrate negative, urease negative, and hydrogen sulfide negative (Koneman et al., 1997). The isolates were serotyped for the $O$ serotype O157 using the O157 Latex Agglutination test kit (Oxoid). Negative isolates were 
considered non-O157 strains. E. coli EDL 933 strain was used as a positive control for $\mathrm{O} 157$ serogroup. All isolates were confirmed as being $E$. coli by their biochemical analysis and submitted to PCR for the detection of stx, eae, and ehly genes. From each MacConkey agar plate, a loopful from a confluent bacterial growth was collected and analyzed. From each plate positive for E. coli, reisolation for individual colonies was done and the isolated colonies were used for polymerase chain reaction (PCR) and susceptibility testing.

\section{PCR screening of samples}

Bacterial strains grown overnight in nutrient broth (Sigma) at $37^{\circ} \mathrm{C}$ were pelleted by centrifugation at $12,000 \mathrm{~g}$ for $1 \mathrm{~min}$, resuspended in $200 \mu \mathrm{L}$ of sterile distilled water, and lysed by boiling for $10 \mathrm{~min}$. Lysates were centrifuged as described above, and $150 \mu \mathrm{L}$ of the supernatants was used as DNA template for the PCR (Wani et al., 2003). A total of $85 \mathrm{E}$. coli isolates were subjected to PCR; st $x 1$, st $x 2$, and eae genes were detected using the primers and PCR conditions described by China et al. (1996). Control reference strains were E. coli EDL 933 (O157:H7, stx1, stx2, eae) and E. coli K12 (negative control).

\section{Expression of ehly}

Expression of enterohemolysin was determined as described by Beutin et al. (1989). Plates were incubated at $37^{\circ} \mathrm{C}$ for $24 \mathrm{~h}$ and observed for hemolysis after $3 \mathrm{~h}$ (for expression of $\alpha$ hemolysin) and $24 \mathrm{~h}$ (for ehly), respectively, and the genotype was confirmed by PCR using the primers hlyA1 and hlyA4 described by Schmidt et al. (1995). The reference strains used in this assay were E. coli U4-41 (positive control for $\alpha$-hemolysin), E. coli 32511 (STEC O157:H7) (positive control for ehly), and E. coli K12 (negative control).

\section{Susceptibility testing}

Antimicrobial disk susceptibility tests were performed using the disk diffusion method, as recommend by the National Committee for Clinical Laboratory Standards (NCCLS, 2002). From each E. coli-positive plate, one isolated colony was tested against 11 antimicrobial agents: ampicillin, amoxicillin/clavulanic acid, cephalothin, ceftriaxone, tetracycline, gentamicin, streptomycin, amikacin, cotrimoxazole, nalidixic acid, and ciprofloxacin. E. coli reference strains ATCC 25922 and ATCC 35218 were used for strain quality control.

\section{Results}

The distribution of positive carcass responses for E. coli corresponding to each sampling season is shown in Table 1. At the postprocessing stage, $32 \%(37 / 116)$ of the carcasses sampled were E. coli positive, showing that the isolation of $E$. coli was twice as high $(44 \%, 25 / 56)$ in the rainy season when compared to the dry season $(20 \%, 12 / 60)$. In the fourth collection, at the dry season, a reduction was detected in the E. colipositive carcasses at the postevisceration stage $(38 \%, 19 / 50)$ when compared with the preevisceration stage $(55 \%, 29 / 50)$.

Among the 216 carcasses analyzed, only 3 $(1.4 \%)$ (data not shown) were positive for stx genes in E. coli isolates when submitted to PCR analysis. One of the three was positive for the st $x 1$, and the other two for st $x 1 /$ st $x 2$ genes;

Table 1. Distribution of Escherichia coli Isolates from Three Different Stages of Processing of 216 Beef Carcasses at an Abattoir During Two Different Climatic Seasons in Brazil, Between February 2006 AND JUNE 2007

\begin{tabular}{lccccc}
\hline $\begin{array}{c}\text { Carcass } \\
\text { Collection }\end{array}$ & Season & Preevisceration & Postevisceration & Postprocessing & Number of positive carcass/total \\
\hline $1^{\circ}$ & Dry & NS & NS & $12 / 60$ & $12 / 60$ \\
$2^{\circ}$ & Rainy & NS & NS & $3 / 16$ & $3 / 16$ \\
$3^{\circ}$ & Rainy & NS & NS & $22 / 40$ & $22 / 40$ \\
$4^{\circ}$ & Dry & $29 / 50$ & $19 / 50$ & NS & $48 / 100$ \\
& & & & & $85 / 216$ \\
\hline
\end{tabular}

NS, not searched for. 


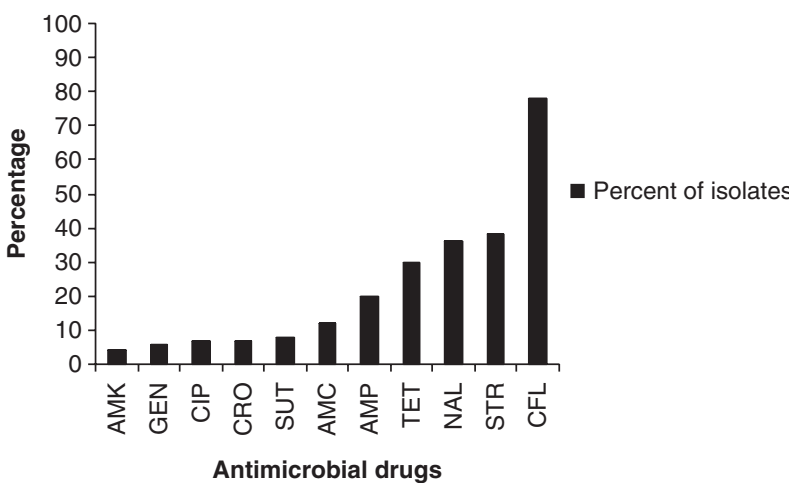

FIG. 1. Antimicrobial resistance patterns of 85 Escherichia coli strains of cattle from an abattoir in Brazil. AMC, amoxicillin/clavulanic acid; AMK, amikacin; AMP, ampicillin; $\mathrm{CRO}$, ceftriaxone; CFL, cephalothin; CIP, ciprofloxacin; GEN, gentamicin; NAL, nalidixic acid; STR, streptomycin; TET, tetracycline; SUT, cotrimoxazole.

all of the isolates were negative for genes eae and ehly.

Antibiotic resistance patterns of the isolates $(n=85)$ are presented in Fig. 1. Isolates presenting intermediary resistance were classified as resistant. The most frequent resistances were to cephalothin $(78 \%)$, streptomycin $(38 \%)$, nalidixic acid $(36 \%)$, and tetracycline $(30 \%)$, and were less frequent to amikacin $(4.0 \%)$ and gen- tamicin (6.0\%). No antimicrobial resistance was determined in nine $(10 \%)$ isolates. Multidrug resistance (MDR) to three or more antimicrobial agents was shown by $28(33 \%)$ of the E. coli isolates, and the most common MDR pattern was to streptomycin, tetracycline, and cephalothin (Table 2).

\section{Discussion}

E. coli strains are part of the microbiota of the gastrointestinal tract of cattle raised for human meat consumption. Transfer of fecal material to the carcass at slaughtering leads to potential contamination of raw meat (Elder et al., 2000). In the present study, the collection dates of each material are not exactly comparable because of the size of samples and the fact that all three points were not collected on the same sampling days. Based on the first, second, and third sample collection, we verified that the isolation of E. coli from the carcasses examined was twice as high in the rainy season when compared to the dry season, confirming other reports (Barkocy-Gallagher et al., 2001; VarelaHernandez et al., 2007). In the fourth collection at the dry season, a reduction in the E. coli car-

Table 2. Resistance Patterns of 28 Multidrug-Resistant Escherichia coli Strains Isolated from Cattle CARCASSEs During Slaughtering

\begin{tabular}{|c|c|c|c|c|c|c|c|c|c|c|c|}
\hline Number of strains & $A M P^{\mathrm{a}}$ & $A M K$ & STR & GEN & TET & CRO & CFL & $A M C$ & $N A L$ & CIP & SUT \\
\hline 6 & & & + & & + & & + & & & & \\
\hline 2 & + & & + & & + & & + & & + & & \\
\hline 2 & + & & + & & + & & + & + & & & \\
\hline 1 & & & & & & & + & & + & & + \\
\hline 1 & & & + & & & & + & & + & & \\
\hline 1 & & & + & & + & & + & & + & & \\
\hline 1 & & & + & & & + & + & & & & \\
\hline 1 & + & & & & + & & + & + & & & \\
\hline 1 & & + & + & & + & & + & & & & \\
\hline 1 & + & & + & & & & + & & + & & \\
\hline 1 & & & & & & & + & + & + & & + \\
\hline 1 & + & & & & & & + & + & & & + \\
\hline 1 & & & & & + & & + & & + & & \\
\hline 1 & + & & + & & + & & + & & + & & \\
\hline 1 & + & & + & & & + & + & + & + & & \\
\hline 1 & & & + & + & + & + & + & & + & + & \\
\hline 1 & + & & + & & + & & + & + & + & & \\
\hline 1 & + & & + & + & + & + & + & & & + & \\
\hline 1 & & + & + & + & + & + & & & + & + & \\
\hline 1 & + & & + & & + & + & + & & + & + & + \\
\hline 1 & + & + & + & + & & + & + & + & + & + & \\
\hline
\end{tabular}

${ }^{\mathrm{a}}$ Antimicrobial drugs.

AMP, ampicillin; AMK, amikacin; STR, streptomycin; GEN, gentamicin; TET, tetracycline; CRO, ceftriaxone; CFL, cephalothin; AMC, amoxicillin/clavulanic acid; NAL, nalidixic acid; CIP, ciprofloxacin; SUT, cotrimoxazole. 
casses contamination was detected at the postevisceration stage in agreement with the data reported by Elder et al. (2000) for an U.S. abattoir.

In the present study, a superficial contamination of the carcass by STEC strains was established, but at a low level (1.4\%) that agrees with reports by other authors. Rogerie et al. (2001) reported a low $(1.9 \%)$ postprocessing non-O157 STEC prevalence in carcasses sampled during the summer in processing plants in France. Similarly, the non-O157 STEC prevalence in carcasses processed in Hong Kong has been reported as being of 1.7\% (Leung et al., 2001). However, a different situation has been reported by carcasses processed in Mexico and the United States; Varela-Hernandez et al. (2007) and Arthur et al. (2002) reported a high level of contamination with non-O157 STEC, of $20.5 \%$ and $54.0 \%$, respectively. Because a large number of variables (e.g., management practices, diets fed, animal factors, and methods of STEC detection) can influence STEC prevalence, comparisons among studies should be carefully evaluated.

Traditionally, Brazil is characterized as a beef cattle producer. Animals are fed mainly at pasture, considering they evolved as grazing herbivores. However, cereal grains ferment at a faster rate than fiber, and grain can be a valuable supplement for cattle production. Several studies have suggested continuous feeding of high grain diets that promotes the proliferation of $E$. coli population, lowers the $\mathrm{pH}$ of gut contents, and selects for acid-resistant STEC (DiezGonzales and Russell, 1999; Vanselow et al., 2005), increasing the shedding of enterohemorrhagic E. coli (EHEC O157:H7). These conditions, in addition to the high animal density in feedlot (traditional in the United States), make it reasonable to assume that a selection of acidresistant $E$. coli serotypes in grain-fed cattle differ from those isolated from grazing-fed animals, in number as well as in serotypes.

The low level of STEC strains detected as contaminants in the carcass, in this study, contrasts with the high number of these strains detected in feces of healthy or diarrheic cattle in Brazil (Irino et al., 2005; Rigobelo et al., 2006; Aidar-Ugrinovich et al., 2007) what could suggest a efficient work during removal of the hide or the gastrointestinal tracts during slaughtering.
Absence or rarity of the eae gene observed in STEC isolates coincides with earlier reports in Brazil (Lira et al., 2004; Irino et al., 2005). Absence of serotype O157:H7 in STEC isolates is not unexpected; it is extremely rare $(0.6 \%)$ in Brazilian cattle (Irino et al., 2005), although a gold standard method as a immunomagnetic separation using beads coated with $\mathrm{O} 157$ antibodies was already used to select the STEC O157 strains in feces of cattle (Aidar-Ugrinovich et al., 2007). Magnetic beads labeled with antibodies to alternative non-O157 serotypes are now available commercially, but other aspects of their isolation (e.g., their optimum enrichment media and enrichment temperature) are still in development (Drysdale et al., 2004).

It is not clear to what extent non-O157 STEC bacteria detected in cattle feces or on beef carcasses are able to cause disease in humans. Gyles et al. (1998) proposed that all STEC bacteria could become pathogenic according to the presence or absence of favorable conditions; Bettelheim (2007) claims that non-O157 STEC's ability to cause diseases is, in general, underestimated.

For over 4 decades, it has been a common practice in farms to use antimicrobial agents for animal disease prevention and growth promotion. Pathogenic organisms are clearly the antimicrobial drug's target bacterial population on which selection pressure can be exerted. It is also important to consider that antimicrobial drugs may exert selection pressure on commensal bacteria (Catry et al., 2003).

Levels of antimicrobial resistance in fecal commensal bacteria can reflect the selection pressure exerted by the use of antimicrobial agents in a certain environment (Van den Bogaard and Stobberingh, 1999). In the present study, high levels of resistance as well as MDR were detected among the isolates agreeing with other reports from Brazil (Lira et al., 2004; Rigobelo et al., 2006), all of them showing resistance predominantly to cephalothin, tetracycline, streptomycin, and less frequently to nalidixic acid. These findings agree with data from previous studies showing that resistance is common among strains isolated from food, animals, and humans (Sáenz et al., 2001; Schroeder et al., 2002).

The multiple antimicrobial-resistant phenotypes observed in this study (Table 2) may 
have resulted from the spread of mobile genetic elements. For example, the observation that nearly $62 \%$ of ampicillin-resistant $E$. coli isolates were also resistant to streptomycin and tetracycline suggests that resistance genes for these drugs are linked on plasmids, agreeing with data previously reported by Schroeder et al. (2002) for generic E. coli and STEC strains. High levels of resistance to antimicrobial agents have also been reported for STEC strains isolated in India (Khan et al., 2002), in Europe (Mora et al., 2005), and in Palestine (Adwan and Adwan, 2004) with some strains also exhibiting MDR.

It is generally accepted that antimicrobial resistance in veterinary medicine could form a potential public health hazard. Indeed, the commensal gastrointestinal flora of healthy animals harbors a reservoir of resistance genes (Witte, 2000) that can colonize human flora through the food chain or by direct contact. Underlying resistance horizontal gene transfer to human pathogenic bacteria can result in treatment failures, which constitute a reason for concern (Van den Bogaard and Stobberingh, 2000; Catry et al., 2003).

In conclusion, we report here a small (1.4\%) level of STEC strains on beef carcasses during processing at an abattoir in Brazil. Analyzed $E$. coli isolates showed a high level of antimicrobial resistance as well as MDR, again causes a reason for concern.

\section{Acknowledgment}

The authors thank FAPESP (Grant 04/156004) for financial support.

\section{Disclosure Statement}

No competing financial interests exist.

\section{References}

Acheson DW. How does Escherichia coli O157:H7 testing in meat compare with what we are seeing clinically? J. Food Prot. 2000;63:819-821.

Adwan GM, and Adwan KM. Isolation of Shiga toxigenic Escherichia coli from raw beef in Palestine. Int. J. Food Prot. 2004;97:81-84.

Aidar-Ugrinovich L, Blanco J, Blanco M, Blanco JE, Leomil L, Dahbi G, Mora A, Onuma DL, Silveira WD, and Pestana de Castro AF. Serotypes, virulence genes, and intimin types of Shiga toxin-producing Escherichia coli (STEC) and enteropathogenic E. coli (EPEC) isolated from calves in São Paulo, Brazil. Int. J. Food Microbiol. 2007;115:297-306.

Arthur TM, Barkocy-Gallagher GA, Rivera-Betancourt M, and Koohmaraie M. Prevalence and characterization of Non O157 Shiga toxin-producing Escherichia coli on carcasses in commercial beef cattle processing plants. Appl. Environ. Microbiol. 2002;68:4847-4852.

Barkocy-Gallagher GA, Arthur GA, Siragusa GR, Keen JE, Elder RO, Laegreid WW, and Koohmaraie M. Genotype analyses of Escherichia coli O157:H7 and O157 nonmotile isolates recovered from beef cattle and carcasses at processing plants in the midwestern states of the United States. Appl. Environ. Microbiol. 2001;67:3810-3818.

Bell RG. Distribution and sources of microbial contamination of beef carcasses. J. Appl. Microbiol. 1997;82:292300.

Bettelheim KA. Role of non-O157 VTEC. J. Appl. Microbiol. 2000;88:385-505.

Bettelheim KA. The non-O157 Shiga toxigenic (Verotoxigenic) Escherichia coli; under-rated pathogens. Clin. Microbiol. Rev. 2007;33:67-87.

Beutin L, Geier D, Zimmermann S, Aleksic S, Gillespie HA, and Whittam TS. Epidemiological relatedness and clonal types of natural populations of Escherichia coli strains producing Shiga toxins in separate populations of cattle and sheep. Appl. Environ. Microbiol. 1989;63:2175-2180.

Blanco M, Blanco JE, Blanco J, Mora A, Prado C, Alonso MP, Mourino M, Madrid C, Balsalobre C, and Juarez A. Distribution and characterization of faecal verotoxin producing Escherichia coli (VTEC) isolated from healthy cattle. Vet. Microbiol. 1997;54:309-319.

Caprioli A, Morabito S, Brugere H, and Oswald H. Enterohaemorrhagic Escherichia coli: emerging issues on virulence and modes of transmission. Vet. Res. 2005;36: 289-311.

Catry B, Laevens H, Devriese LA, Opsomer G, and De Kruif A. Antimicrobial resistance in livestock. J. Vet. Pharmacol. Ther. 2003;26:81-93.

China B, Pirson V, and Mainil J. Typing of bovine attaching and effacing Escherichia coli by multiplex amplification of virulence-associated genes. Appl. Environ. Microbiol. 1996;82:3462-3463.

Diez-Gonzalez F, and Russell JB. Factors affecting the extreme acid resistance of Escherichia coli O157: H7. Food Microbiol. 1999;16:367-374.

Drysdale M, MacRae M, Strachan NJC, Reid TMS, and Ogden ID. The detection of non-O157 E. coli in food by immunomagnectic separation. J. Appl. Microbiol. 2004; 97:220-224.

Elder RO, Keen JE, Siragusa GR, Barkocy-Gallagher GA, Koohmarale M, and Laegreid WW. Correlation of enterohemorrhagic Escherichia coli O157 prevalence in feces, hides, and carcasses of beef cattle during processing. Proc. Natl. Acad. Sci. USA 2000;97:2999-3003.

Farah SMSS, de Souza EM, Pedrosa FO, Irino K, da Silva LR, Rigo LU, Steffens MBR, Pigato CP, and FadelPicheth CMT. Phenotypic and genotypic traits of Shiga toxin-producing Escherichia coli strains isolated from beef cattle from Paraná State, southern Brazil. Lett. Appl. Microbiol. 2007;44:607-612. 
Gyles C, Johnson R, Gao A, Ziebell K, Pierard D, Aleksic S, and Boerlin P. Association of enterohemorrhagic Escherichia coli hemolysin with serotypes of Shiga toxin producing E. coli of humans and bovine origins. Appl. Environ. Microbiol. 1998;64:4134-4141.

Hussein HS, and Bollinger LM. Prevalence of Shiga toxinproducing Escherichia coli in beef. Meat Sci. 2005;71: 676-689.

Irino K, Kato MAMF, Vaz TMI, Ramos II, Souza MAC, Cruz AS, Gomes TAT, Vieira MAM, and Guth BEC. Serotypes and virulence markers of Shiga toxinproducing Escherichia coli (STEC) isolated from dairy cattle in São Paulo State, Brazil. Vet. Microbiol. 2005;105: 29-36.

Khan A, Das SC, Ramamurthy T, Sikdar A, Khanam J, Yamasaki S, and Nair GB. Antibiotic resistance, virulence gene, and molecular profiles of Shiga toxinproducing Escherichia coli isolates from diverse source in Calcutta India. J. Clin. Microbiol. 2002;40:2009-2015.

Koneman EW, Allen SD, Schrekenberger PC, Janda WM, and Winn WC. Color atlas and textbook microbiology, fifth edition. Philadelphia, PA: Lippincott Company, 1997.

Leung PH, Yam WC, Ng WW, and Peiris JS. The prevalence and characterization of verotoxin-producing Escherichia coli isolated from cattle and pigs in an abattoir in Hong Kong. Epidemiol. Infect. 2001;126:173-179.

Lira WM, Macedo C, and Marin JM. The incidence of Shiga toxin-producing Escherichia coli in cattle with mastitis in Brazil. J. Appl. Microbiol. 2004;97:861-866.

Monroe S, and Polk R. Antimicrobial use and bacterial resistance. Curr. Opin. Microbiol. 2000;3:496-501.

Mora A, Blanco JE, Blanco M, Alonso Pilar M, Dhabi G, Echeita A, Gonzalez EA, Bernardez MI, and Blanco J. Antimicrobial resistance of Shiga toxin (verotoxin)producing Escherichia coli O157:H7 and non-O157 strains isolated from humans, cattle, sheep and food in Spain. Res. Microbiol. 2005;156:793-806.

Nataro JP, and Kaper JB. Diarrheagenic Escherichia coli. Clin. Microbiol. Rev. 1998;11:142-201.

National Committee for Clinical Laboratory Standards. Performance Standards for Antimicrobial Disk Dilution Susceptibility Test for Bacteria Isolated from Animals Approved Standard M31A2. Wayne, MI: NCCLS, 2002.

Rigobelo EC, Gamez HJ, Marin JM, Macedo C, Ambrosin JÁ, and Ávila FA. Virulence factors of Escherichia coli isolated from diarrheic calves. Arq. Bras. Med. Vet. Zootec. 2006;58:305-310.

Riley LW, Remis RS, Helgerson SD, McGee HB, Wells GJ, Herbert RJ, Olcott ES, Johnson LM, Hargrett NT, Blake PA, and Cohen ML. Hemorrhagic colitis associated with a rare Escherichia coli serotypes. N. Engl. J. Med. 1983; 308:681-685.

Rodolpho D, and Marin JM. Isolation of Shiga toxigenic Escherichia coli from butcheries in Taquaritinga City,
State of São Paulo, Brazil. Braz. J. Microbiol. 2007; 38:599-602.

Rogerie F, Marecat A, Gambade S, Dupond F, Beaubois P, and Lange M. Characterization of Shiga toxin producing Escherichia coli and O157 serotype E. coli isolated in France from healthy domestic cattle. Int. J. Food Microbiol. 2001;63:217-223.

Sáenz Y, Zarazaga M, Brinas I, Lantero M, Ruiz-Larrea F, and Torres C. Antibiotic resistance in Escherichia coli isolates obtained from animals, foods and humans in Spain. Int. J. Antimicrob. Agents 2001;18:353-358.

Schmidt H, Beutin L, and Karch H. Molecular analysis of the plasmid-encoded hemolysis of Escherichia coli O157:H7 strains, EDL 933. Infect. Immun. 1995;63:10551061.

Schroeder CM, Meg J, Zhao S, DebRoy C, Torcolini J, Zhao C, McDermott PF, Wagner DD, Walker RD, and White DG. Antimicrobial resistance of Escherichia coli O26, O103, O111, O128, and O145 from animals and humans. Emerg. Infect. Dis. 2002;8:1409-1414.

Van den Bogaard AEJM, and Stobberingh EE. Antibiotic usage in animals: impact on bacterial resistance and public health. Drugs 1999;58:589-607.

Van den Bogaard AEJM, and Stobberingh EE. Epidemiology of resistance to antibiotic. Links between animals and humans. Int. J. Antimicrob. Agents 2000;14:327-335.

Vanselow BA, Krause DO, and McSweeney CS. The Shiga toxin-producing Escherichia coli, their hosts, and potential on-farm interventions: a review. Aust. J. Agric. Res. 2005;56:219-244.

Varela-Hernandez JJ, Cabrera-Diaz E, Cardona-Lopez MA, Ibarra-Veláquez LM, Rangel-Villalobos H, Castillo A, Torres-Vitela MR, and Ramirez-Alvarez A. Isolation and characterization of Shiga toxin-producing Escherichia coli O157: H7 and non-O157 from beef carcasses at a slaughter plant in México. Int. J. Food Microbiol. 2007;113:237-241.

Wani SA, Bhat MA, Samanta I, Nishikawa Y, and Buchh AS. Isolation and characterization of Shiga toxinproducing Escherichia coli (STEC) and enteropathogenic Escherichia coli (EPEC) from calves and lambs with diarrhea in India. Lett. Appl. Microbiol. 2003;37:121-126.

Witte W. Ecological impact of antibiotic use in animals on different complex microflora: environment. Int. J. Antimicrob. Agents 2000;14:321-325.

Address reprint requests to: Jose Moacir Marin, Ph.D.

Departamento de Morfologia Estomatologia e Fisiologia, FORP Universidade de São Paulo-Campus Ribeirão Preto 14040-904 Brazil

E-mail: jmmarin@forp.usp.br 
